\title{
KAJIAN KESESUAIAN WISATA PANTAI KELURAHAN MATRAS BANGKA DITINJAU DARI ASPEK BIOGEOFISIK
}

\author{
Sari Novita Dewi ${ }^{(1)}$, Wahyu Adi ${ }^{(2)}$, Indra Ambalika Syari ${ }^{(2)}$ \\ (1) Mahasiswa Jurusan Manajemen Sumberdaya Perairan FPPB Universitas Bangka Belitung \\ (2) Staff Pengajar Jurusan Manajemen Sumberdaya Perairan FPPB Universitas Bangka Belitung \\ Sarinovitadewi48@gmail.com
}

\begin{abstract}
Abstrak
Kabupaten Bangka sudah mulai mengembangkan sector pariwisata yakni dengan membentuk Desa wisata Kelurahan Matras salah satu kawasan wisata yang dimiliki Kabupaten Bangka. Penelitian ini untuk menganalisis kajian kesesuaian lahan wisata ditinjau dari aspek biogeofisik. Pengambilan data dilakukan pada Bulan April 2016 di pantai di Kelurahan Matras yaitu Pantai Matras, Tanjung Kelayang, Turun Aban, Parai tenggiri dan Batu Bedaun. Analisis data didasarkan pada matrik Indeks Kesesuain Wisata (IKW). Hasil penelitian nilai IKW (Indeks Kesesuaian Wisata) pada Pantai Matras yaitu 96,29\%, Pantai Tanjung Kelayang ;92,593\%, Pantai Turun Aban dan Pantai Parai Tenggiri ; 96,296\%, Pantai Batu Bedaun ; 100\%. Kajian yang dilakukan pada pantai di Kelurahan Matras menunjukkan kawasan pantai di Kelurahan Matras mendapatkan hasil untuk semua stasiun adalah sangat sesuai (S1). Analisis kesesuaian lahan wisata semua stasiun termasuk kategori sangat sesuai untuk kriteria wisata.
\end{abstract}

Kata Kunci : Kesesuaian, wisata pantai, Matras

\section{PENDAHULUAN}

Kabupaten Bangka adalah salah satu dari enam kabupaten yang ada di Provinsi Kepulauan Bangka Belitung sudah mulai mengembangkan sektor wisata.Kabupaten Bangka dapat ditempuh dengan jarak sekitar $40 \mathrm{~km}$ dari Kota Pangkalpinang.Kabupaten Bangka memiliki banyak kawasan wisata pantai dan salah satunya adalah kawasan wisata pantai di Kelurahan Matras. Menurut Perda Kabupaten Bangka No 01 tahun 2013 tentang tata ruang wilayah kabupaten tentang kawasan Matras dan sekitarnya akan dimanfaatkan sebagai kawasan wisata.

Kelurahan Matras dapat ditempuh sekitar satu jam dari kota Pangkalpinang atau sekitar 15-20 menit dari pusat Kota Sungailiat. Kelurahan Matras merupakan salah satu kelurahan yang saat ini sudah dinyatakan sebagai kelurahan wisata diantaranya ada Pantai Batu Bedaun, Pantai Parai Tenggiri, Pantai Turun Aban, Pantai Tanjung Kelayang dan Pantai Matras. Selain memiliki banyak tempat wisata kawasan ini pun mudah untuk ditempuh karena jaraknya cukup dekat sehingga banyak wisatawan berminat untuk datang berkunjung ke daerah tersebut. Jumlah kunjungan yang bertambah juga harus didukung pengelolaan yang baik guna memenuhi kepuasan minat wisatawan. Pengelolaan yang baik harus didukung oleh data sumberdaya mengenai potensinya dari aspek biogeofisik.Hasil penelitian ini juga diharapkan dapat menjadi masukan bagi pemerintah maupun pihak pengelolaan lainnya.

Tujuan dari penelitian ini adalah Menganalisis indeks kesesuaian wisata ditinjau dari aspek biogeofisik (biologi, geomorfologi dan fisika) pada pantai di Kelurahan Matras Kabupaten Bangka.
Pariwisata menurut Krapt dan Hunziker dalam Yoeti (1996) adalah keseluruhan dari gejala-gejala yang ditimbulkan dari perjalanan dan pendiaman orang-orang asing serta penyediaan tempat tinggal sementara, asalkan orang asing itu tidak tinggal menetap dan tidak memperoleh penghasilan dari aktivitas yang bersifat sementara. Wisata adalah kegiatan perjalanan atau sebagian dari kegiatan tersebut yang dilakukan secara sukarela serta bersifat sementara untuk menikmati obyek dan daya tarik wisata (Undang-undang No 10 tahun 2009).Wisata pantai kategori rekreasi merupakan jenis kegiatan yang paling dominan di daerah pantai.Kegiatan rekreasi memanfaatkan sumberdaya pantai seperti pasir putih, hamparan pantai, pemandangan (view), biota dan perairan pantainya (Hutabarat et.al, 2009).

Pemanfaatan kawasan wisata dalam hal kegiatan wisata pantai, biogeofisik dimaksudkan sebagai salah satu bidang kajian berbasis edukasi atau pendidikan misalnya dalam kegiatan wisata memperkenalkan tumbuhan pantai kepada wisatawan disertai dengan kegiatan fisik lainnya seperti kegiatan bermain dan berenang. Beberapa parameter biogeofisik yang terkait untuk penentuan suatu kawasan wisata pantai antara lain yaitu identifikasi penutupan lahan pantai, tipe pantai, lebar pantai, kemiringan pantai, pasang surut, kedalaman, kecepatan arus, kecerahan dan ketersediaan air tawar. Analisis kesesuaian lahan salah satunya dilakukan untuk mengetahui kesesuaian kawasan bagi pengembangan wisata. Kelas kesesuaian yang digunakan untuk mengetahui kesesuaian wisata pantai dan bahari dibagi dalam 4 kategori yaitu kategori sangat sesuai (S1) dengan nilai $75-100 \%$, sesuai (S2) dengan nilai $50-<75 \%$, sesuai bersyarat (S3) dengan nilai $25-$ 
$<50 \%$, dan tidak sesuai (TS) dengan nilai $<25 \%$ (Yulianda, 2007).

\section{METODE}

Penelitian ini dilakukan pada bulan April 2016 di lima pantai yang ada di Kelurahan Matras, yaitu Pantai Matras, Tanjung Kelayang, Turun Aban, Parai Tenggiri, dan Batu Bedaun.

Metode penelitian yang digunakan adalah metode purposive sampling dengan menggunakan GPS dalam menentukan titik pengambilan data.Satu pantai terdiri atas tiga titik pengambilan data. Satu titik pengambilan data terdiri atas sembilan parameter yaitu kedalaman, tipe pantai, lebar pantai, kecepatan arus, kemiringan, penutupan lahan pantai, kecerahan perairan, pasang surut dan ketersediaan air tawar. Pengambilan data dilapangan disesuaikan dengan kondisi yang ada dilapangan. Data-data yang diperoleh kemudian dianalisis dengan berdasarkan matrik indeks kesesuaian wisata (IKW) menurut Yulianda, 2007 dapat dilihat pada Tabel 1 dan 2 serta dihitung dengan menggunakan rumus sebagai berikut :

$$
I K W=\sum\left[\frac{N i}{N m a k s}\right] x 100 \%
$$

Keterangan:

$\begin{array}{ll}\mathrm{IKW} & =\text { Indeks kesesuaian wisata } \\ \mathrm{Ni} & =\text { Nilai parameter ke-I (bobot } \mathrm{x} \text { skor) } \\ \mathrm{Nmaks} & =\text { Nilai Maksimum dari suatu kategori }\end{array}$

Tabel.1 Matrik kesesuaian wisata pantai

\begin{tabular}{|c|c|c|c|c|c|c|c|c|c|c|}
\hline \multirow[b]{2}{*}{ Z } & \multirow[t]{2}{*}{ Parameter } & \multirow[b]{2}{*}{$\begin{array}{l}\mathscr{\sigma} \\
\stackrel{0}{0} \\
\stackrel{+}{+}\end{array}$} & \multirow{2}{*}{$\begin{array}{l}\text { Kategori } \\
\text { S1 }\end{array}$} & \multicolumn{3}{|c|}{ Kategori } & \multirow[t]{2}{*}{ Kategori S3 } & \multicolumn{3}{|c|}{ Kategori TS } \\
\hline & & & & $\stackrel{n}{\grave{c}}$ & $\mathrm{~S} 2$ & $\frac{\mathscr{2}}{\operatorname{T}}$ & & $\stackrel{\mathscr{2}}{\pi}$ & & $\stackrel{2}{\hat{O}}$ \\
\hline 1 & $\begin{array}{l}\text { Kedalaman Perairan } \\
(\mathrm{cm})\end{array}$ & 5 & $0-300$ & 3 & $300-600$ & 2 & $600-900$ & 1 & $>900$ & 0 \\
\hline 2 & Tipe Pantai & 5 & Pasir putih & 3 & $\begin{array}{c}\text { Pasir } \\
\text { putih } \\
\text { sedikit } \\
\text { karang }\end{array}$ & 2 & $\begin{array}{l}\text { Pasir hitam } \\
\text { berkarang } \\
\text { sedikit terjal }\end{array}$ & 1 & $\begin{array}{c}\text { Lumpur berbatu } \\
\text { terjal }\end{array}$ & 0 \\
\hline 3 & Lebar Pantai m & 5 & $>15$ & 3 & $10-15$ & 2 & $3-<10$ & 1 & $<3$ & 0 \\
\hline 4 & Kecepatan Arus (m/s) & 3 & $0-0,17$ & 3 & $0,17-0,34$ & 2 & $0,34-0,51$ & 1 & $>0,51$ & 0 \\
\hline 5 & Kemiringan $\left({ }^{\circ}\right)$ & 3 & $<10$ & 3 & $10-25$ & 2 & $>25-45$ & 1 & $>45$ & 0 \\
\hline 6 & $\begin{array}{c}\text { Penutupan Lahan } \\
\text { Pantai }\end{array}$ & 3 & $\begin{array}{l}\text { Kelapa, } \\
\text { lahan } \\
\text { terbuka }\end{array}$ & 3 & $\begin{array}{l}\text { Semak, } \\
\text { belukar } \\
\text { rendah, } \\
\text { savanna }\end{array}$ & 2 & Belukar tinggi & 1 & $\begin{array}{c}\text { Hutan bakau, } \\
\text { pemukiman } \\
\text { penduduk, } \\
\text { pelabuhan }\end{array}$ & 0 \\
\hline 7 & Kecerahan (\%) & 1 & $>75 \%$ & 3 & $\begin{array}{l}>50 \%- \\
75 \%\end{array}$ & 2 & $25 \%-50 \%$ & 1 & $<25 \%$ & 0 \\
\hline 8 & Pasang Surut & 1 & $0-1$ & 3 & $>1-2$ & 2 & $>2-5$ & 1 & $>5$ & 0 \\
\hline 9 & $\begin{array}{l}\text { Ketersediaan air } \\
\text { tawar }(\mathrm{m})\end{array}$ & 1 & $<500$ & 3 & $500-1000$ & 2 & $1000-2000$ & 1 & $>2000$ & 0 \\
\hline
\end{tabular}

Tabel.2 Kelas indeks kesesuaian wisata

\begin{tabular}{ccc}
\hline No & Kelas kesesuaian & Keterangan \\
\hline 1 & S1 & $75-100 \%$ \\
2 & S2 & $50-<75 \%$ \\
3 & S3 & $25-<50 \%$ \\
4 & TS & $<25 \%$ \\
\hline
\end{tabular}

\section{HASIL DAN PEMBAHASAN}

Analisis kesesuaian lahan pada Pantai Matras dapat dilihat pada Tabel.3 didapatkan hasil kategori sangat sesuai dengan nilai IKW yaitu 96,29\%.

Pantai Matras sangat sesuai pada parameter kedalaman, tipe pantai, lebar pantai, kemiringan, penutupan lahan, ketersediaan air tawar, kecerahan dan pasang surut.Parameter yang termasuk dalam kategori sesuai adalah parameter kecepatan arus.Kecepatan arus sendiri erat kaitannya dengan keamanan kegiatan wisata renang. Menurut Yulianda (2007) kisaran nilai kecepatan arus yang sangat sesuai adalah $0-0,17 \mathrm{~m} / \mathrm{s}$ nilai kecepatan arus untuk Pantai Matras sendiri adalah $0,194 \mathrm{~m} / \mathrm{s}$.

Analisis kesesuaian lahan pada Pantai Tanjung Kelayang dapat dilihat pada Tabel.4 didapatkan hasil kategori sangat sesuai dengan nilai IKW yaitu 96,296\%.Pantai Tanjung Kelayang didapatkan semua parameter termasuk sangat sesuai.Paramater terendah 
didapatkan pada nilai untuk parameter penutupan lahan pantai. Parameter penutupan lahan juga erat berkaitan dengan kenyamanan wisatawan dalam melakukan aktivitas wisata juga kita dapat mengetahui seberapa luas area yang dapat dimanfaatkan untuk melakukan kegiatan wisata. Pengukuran lebar pantai melibatkan penutupan lahan karena pengukurannya dimulai dari vegetasi terakhir hingga batas pasang tertinggi (Widiatmaka, 2007).

Analisis kesesuaian lahan pada Pantai Turun Aban dapat dilihat pada Tabel.5 didapatkan hasil kategori sangat sesuai dengan nilai IKW yaitu 96,296\%.Pantai Turun Aban hampir semuanya termasuk kategori sangat sesuai.Nilai parameter terendah

Tabel.3 Pantai Matras

\begin{tabular}{|c|c|c|c|c|c|}
\hline No & Parameter & Bobot & Hasil & Skor & $\mathrm{Ni}$ \\
\hline 1 & Kedalaman $(\mathrm{cm})$ & 5 & 200 & 3 & 15 \\
\hline 2 & Tipe Pantai & 5 & Pantai pasir putih & 3 & 15 \\
\hline 3 & Lebar Pantai (m) & 5 & 53,90 & 3 & 15 \\
\hline 4 & Kecepatan Arus (m/s) & 3 & 0,194 & 2 & 6 \\
\hline 5 & Kemiringan $\left({ }^{\circ}\right)$ & 3 & 4,67 & 3 & 9 \\
\hline 6 & Penutupan Lahan & 3 & $\begin{array}{c}\text { Lahan terbuka dan } \\
\text { pohon kelapa }\end{array}$ & 3 & 9 \\
\hline 7 & Kecerahan $(\%)$ & 1 & 100 & 3 & 3 \\
\hline 8 & Pasang Surut (m) & 1 & 1,64 & 3 & 3 \\
\hline 9 & Ketersediaan air tawar (m) & 1 & 142,33 & 3 & 3 \\
\hline \multicolumn{4}{|c|}{ Total } & & 78 \\
\hline \multicolumn{4}{|c|}{ IKW \% } & & 96,29 \\
\hline \multicolumn{4}{|c|}{ Kategori } & & S1 \\
\hline
\end{tabular}

$\underline{\text { Tabel.4 Pantai Tanjung Kelayang }}$

\begin{tabular}{|c|c|c|c|c|c|}
\hline No & Parameter & Bobot & Hasil & Skor & $\mathrm{Ni}$ \\
\hline 1 & Kedalaman $(\mathrm{cm})$ & 5 & 32 & 3 & 15 \\
\hline 2 & Tipe Pantai & 5 & Pantai pasir putih & 3 & 15 \\
\hline 3 & Lebar Pantai (m) & 5 & 20,33 & 3 & 15 \\
\hline 4 & Kecepatan Arus (m/s) & 3 & 0,069 & 3 & 9 \\
\hline 5 & Kemiringan $\left({ }^{\circ}\right)$ & 3 & 8,33 & 3 & 9 \\
\hline 6 & Penutupan lahan & 3 & Belukar tinggi dan kelapa & 1 & 3 \\
\hline 7 & Kecerahan $(\%)$ & 1 & 100 & 3 & 3 \\
\hline 8 & Pasang Surut (m) & 1 & 1,64 & 3 & 3 \\
\hline 9 & Ketersediaan Air Tawar (m) & 1 & 236 & 3 & 3 \\
\hline \multicolumn{4}{|c|}{ Total } & & 75 \\
\hline \multicolumn{5}{|c|}{ IKW \% } & 92,59 \\
\hline \multicolumn{5}{|c|}{ Kategori } & $\mathrm{S} 1$ \\
\hline
\end{tabular}

Tabel.5 Pantai Turun Aban

\begin{tabular}{cccccc}
\hline No & Parameter & Bobot & Hasil & Skor & Ni \\
\hline 1 & Kedalaman (cm) & 5 & 56 & 3 & 15 \\
2 & Tipe Pantai & 5 & Pantai pasir putih & 3 & 15 \\
3 & Lebar Pantai (m) & 5 & 20,33 & 3 & 15 \\
4 & Kecepatan Arus (m/s) & 3 & 0,084 & 3 & 9 \\
5 & Kemiringan $\left({ }^{\circ}\right)$ & 3 & 13,33 & 2 & 6 \\
6 & Penutupan Lahan & 3 & Pohon kelapa dan lahan & 3 & 9 \\
7 & Kecerahan (\%) & 1 & terbuka & 3 & 3 \\
8 & Pasang Surut (m) & 1 & 100 & 3 & 3 \\
9 & Ketersediaan Air Tawar & 1 & 165 & 3 & \\
& $(\mathrm{~m})$ & & & 3 \\
\hline
\end{tabular}

didapatkan pada jenis parameter kemiringan pantai. Pantai jenis ini sangat cocok dijadikan tempat kegiatan wisata sedangkan pada Stasiun 3 parameter kemiringan pantai yaitu $13,33^{\circ}$ nilai ini melebihi dari nilai kemiringan pantai yang cocok untuk kegiatan wisata. Parameter kemiringan pantai juga berkaitan erat dengan kedalaman yakni batas keamanan renang. Semakin mendekati arah curam atau terjal dan ini akan berpengaruh pada batas aman kedalaman untuk melakukan aktifitas berenang. Kemiringan lereng yang datar sampai landai sangat sesuai untuk wisata pantai seperti kegiatan mandi dan renang serta berjemur dan sebagainya (Purbani, 1999). tinggi nilai kemiringan maka jenis pantai akan semakin 


\begin{tabular}{ccc}
\hline Total & 78 \\
\hline IKW \% & 96,296 \\
\hline Kategori & S1 \\
\hline
\end{tabular}

Analisis kesesuaian lahan lahan pada Pantai Parai Tenggiri dapat dilihat pada Tabel.6 didapatkan hasil kategori sangat sesuai dengan nilai IKW yaitu 96,296\%.Pantai Parai Tenggiri hampir semuanya termasuk kategori sangat sesuai. Kemiringan pada Pantai Parai Tenggiri yaitu $11,33^{\circ}$. Parameter kemiringan pantai berkaitan dengan kedalaman yakni batas keamanan renang. Semakin tinggi nilai kemiringan maka jenis pantai akan semakin mendekati arah curam atau terjal dan ini akan berpengaruh pada batas aman kedalaman untuk melakukan aktifitas berenang. Kemiringan lereng yang datar sampai landai sangat sesuai untuk wisata pantai seperti kegiatan mandi dan renang serta berjemur dan sebagainya (Purbani, 1999).
Analisis kesesuaian lahan lahan pada Pantai Batu Bedaun dapat dilihat pada Tabel.7 didapatkan hasil kategori sangat sesuai dengan nilai IKW yaitu $100 \%$.Semua parameter pada stasiun ini termasuk kategori sangat sesuai (S1). Lahan wisata yang baik digunakan untuk kegiatan wisata adalah lahan yang parameternya saling mendukung satu sama lainnya. Analisis kesesuaian lahan salah satunya untuk mengetahui kesesuaian kawasan guna menjadi dasar untuk mengatahui kemampuan wilayah dalam mendukung kegiatan yang dapat dilakukan pada kawasan tersebut bagi pengembangan wisata (Pragawati, 2009).

Tabel.6 Pantai Parai Tenggiri

\begin{tabular}{|c|c|c|c|c|c|}
\hline No & Parameter & Bobot & Hasil & Skor & $\mathrm{Ni}$ \\
\hline 1 & Kedalaman $(\mathrm{cm})$ & 5 & 21 & 3 & 15 \\
\hline 2 & Tipe Pantai & 5 & Pantai pasir putih & 3 & 15 \\
\hline 3 & Lebar Pantai (m) & 5 & 16,71 & 3 & 15 \\
\hline 4 & Kecepatan Arus (m/s) & 3 & 0,021 & 3 & 9 \\
\hline 5 & Kemiringan $\left({ }^{\circ}\right)$ & 3 & 11,33 & 2 & 6 \\
\hline 6 & Penutupan Lahan & 3 & $\begin{array}{c}\text { Lahan terbuka, kelapa, } \\
\text { semak belukar tinggi }\end{array}$ & 3 & 9 \\
\hline 7 & Kecerahan $(\%)$ & 1 & 100 & 3 & 3 \\
\hline 8 & Pasang Surut (m) & 1 & 1,64 & 3 & 3 \\
\hline 9 & $\begin{array}{l}\text { Ketersediaan Air Tawar } \\
(\mathrm{m})\end{array}$ & 1 & 95 & 3 & 3 \\
\hline \multicolumn{5}{|c|}{ Total } & 78 \\
\hline \multicolumn{5}{|c|}{ IKW \% } & 96,296 \\
\hline \multicolumn{5}{|c|}{ Kategori } & $\mathrm{S} 1$ \\
\hline
\end{tabular}

Tabel.7 Pantai Batu Bedaun

\begin{tabular}{|c|c|c|c|c|c|}
\hline No & Parameter & Bobot & Hasil & Skor & $\mathrm{Ni}$ \\
\hline 1 & Kedalaman (cm) & 5 & 10 & 3 & 15 \\
\hline 2 & Tipe Pantai & 5 & Pantai pasir putih & 3 & 15 \\
\hline 3 & Lebar Pantai (m) & 5 & 54,33 & 3 & 15 \\
\hline 4 & Kecepatan Arus (m/s) & 3 & 0,033 & 3 & 9 \\
\hline 5 & Kemiringan $\left(^{\circ}\right)$ & 3 & 7,67 & 3 & 9 \\
\hline 6 & Penutupan Lahan & 3 & $\begin{array}{c}\text { pohon kelapa, lahan } \\
\text { terbuka }\end{array}$ & 3 & 9 \\
\hline 7 & Kecerahan $(\%)$ & 1 & 100 & 3 & 3 \\
\hline 8 & Pasang Surut (m) & 1 & 1,64 & 3 & 3 \\
\hline 9 & $\begin{array}{l}\text { Ketersediaan Air Tawar } \\
(\mathrm{m})\end{array}$ & 1 & 180 & 3 & 3 \\
\hline \multicolumn{5}{|c|}{ Total } & 81 \\
\hline \multicolumn{5}{|c|}{ IKW \% } & 100 \\
\hline \multicolumn{5}{|c|}{ Kategori } & $\mathrm{S} 1$ \\
\hline
\end{tabular}


Hasil kajian kesesuaian lahan wisata pantai yang dilakukan di pantai di Kelurahan Matras didapatkan kategori untuk semua stasiun adalah sangat sesuai (S1). Perbedaan nilai pada hasil penjumlahan perhitungan IKW pada semua stasiun tidak begitu jauh berbeda.Perbedaan nilai ini disebabkan karena jarak antara stasiun satu dengan lainnya yang tidak begitu jauh.Nilai indeks kesesuaian wisata untuk wisata pantai diperlukan untuk mengetahui kesesuaian wilayah pantai untuk kegiatan wisata berdasarkan faktor yang mempunyai nilai penting terhadap pengelolaannya.Kesesuaian kawasan dilihat dari tingkat persentase kesesuaian yang diperoleh penjumlahan nilai dari seluruh parameter (Yulianda, 2007).

\section{KESIMPULAN}

Dari penelitian yang telah dilakukan di Kelurahan Matras Kabupaten Bangka dapat disimpulkan Analisis kesesuaian wisata pada pantai di Kelurahan Matras Kabupaten Bangka ditinjau dari aspek biogeofisik didapatkan nilai IKW (Indeks Kesesuaian Wisata) yaitu Pantai Matras yaitu 96,296\%, Pantai Tanjung Kelayang; 92,593\%, Pantai Turun Aban dan Parai Tenggiri; 96,296\%, Pantai Batu Bedaun: 100\%. Analisis yang dilakukan menunjukkan semua stasiun termasuk dalam kategori sangat sesuai (S1)

\section{DAFTAR PUSTAKA}

Hutabarat AA, Yulianda F, Fahrudin A, Hartati S dan Kusharjani. 2009. Pengelolaan Pesisir dan Laut Secara Terpadu. PUSDIKLAT KEHUTANAN DEPARTEMEN KEHUTANAN RI SECEM KOREA INTERNATIONAL COOPERATION AGENCY. Bogor

Noor YR, Khazali M, Suryadiputra NN. 2006. Panduan Pengenalan Mangrove di Indonesia. PHKA/WIIP, Bogor.

Peraturan Daerah No. 11 tahun2012 mengenai Pembentukan Kelurahan Sinar Jaya Jelutung, Kelurahan Matras, Kelurahan Jelitik, Kelurahan Surya Timur, Kelurahan Lubuk Keli, Kelurahan Bukit Betung dalam Wilayah Kecamatan Sungailiat di Kabupaten Bangka.

Pragawati, B. 2009. Pengelolaan Sumberdaya Pesisir Untuk Pengembangan Ekowisata Bahari Di Pantai Binangun, Kabupaten Rembang, Jawa Tengah. [Skripsi]. Bogor : Fakultas Perikanan, Institut Pertanian Bogor.

Purbani, D. 1999. Aplikasi Geografi Fisik Indonesia Kawasan Wisata Pesisir di Pulau Lombok. Pasca Sarjana Ilmu Geografi UI.Jakarta.

Simond, J. O., 1978, Eartscape, New York: McGraw Hill Book Company.

Undang Undang Republik Indonesia No. 10 Tahun 2009 Tentang Kepariwisataan

Widiatmaka, S. 2007. Evaluasi Kesesuaian Lahan dan Perencanaan Tata Guna Lahan.Gadjah Mada University Press. Yogyakarta.

Yoeti, O. A.1996. Pengantar Ilmu Pariwisata. Angkasa. Bandung
Yulianda, F. 2007. Ekowisata Bahari Sebagai Alternatif Pemanfaatan Sumberdaya Pesisir Berbasis Konservasi. Disampaikan pada Seminar Sains 21 Februari 2007 pada Departemen Manajemen Sumberdaya Perairan, FPIK.IPB 